
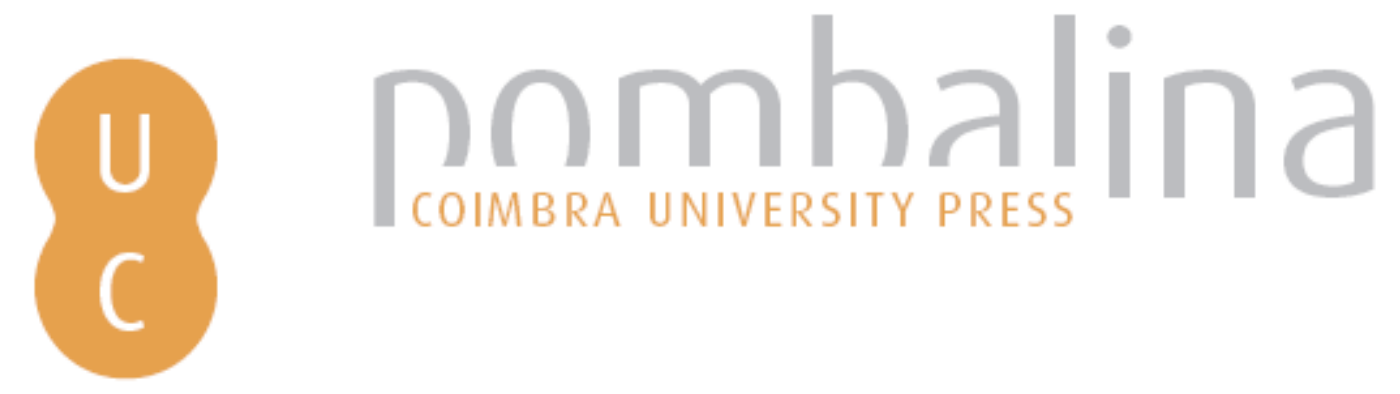

\title{
Lille: leitura do território e estratégia urbana (para a água/pela água)
}

Autor(es): $\quad$ Lemeiter, Richard; Pinon, Julien; Riviere, Cédric

Publicado por: Imprensa da Universidade de Coimbra

URL

persistente:

URI:http://hdl.handle.net/10316.2/39323

DOI:

DOI:http://dx.doi.org/10.14195/978-989-26-1025-2_8

Accessed : $\quad$ 26-Apr-2023 13:51:56

A navegação consulta e descarregamento dos títulos inseridos nas Bibliotecas Digitais UC Digitalis, UC Pombalina e UC Impactum, pressupõem a aceitação plena e sem reservas dos Termos e Condições de Uso destas Bibliotecas Digitais, disponíveis em https://digitalis.uc.pt/pt-pt/termos.

Conforme exposto nos referidos Termos e Condições de Uso, o descarregamento de títulos de acesso restrito requer uma licença válida de autorização devendo o utilizador aceder ao(s) documento(s) a partir de um endereço de IP da instituição detentora da supramencionada licença.

Ao utilizador é apenas permitido o descarregamento para uso pessoal, pelo que o emprego do(s) título(s) descarregado(s) para outro fim, designadamente comercial, carece de autorização do respetivo autor ou editor da obra.

Na medida em que todas as obras da UC Digitalis se encontram protegidas pelo Código do Direito de Autor e Direitos Conexos e demais legislação aplicável, toda a cópia, parcial ou total, deste documento, nos casos em que é legalmente admitida, deverá conter ou fazer-se acompanhar por este aviso. 


\section{LILLE \\ LEITURA DO TERRITÓRIO E ESTRATÉGIA URBANA (PARA A AGUA/PELA ÁGUA)}

RICHARD LEMEITER (Coordenador)

JULIEN PINON

CÉDRIC RIVIERE 


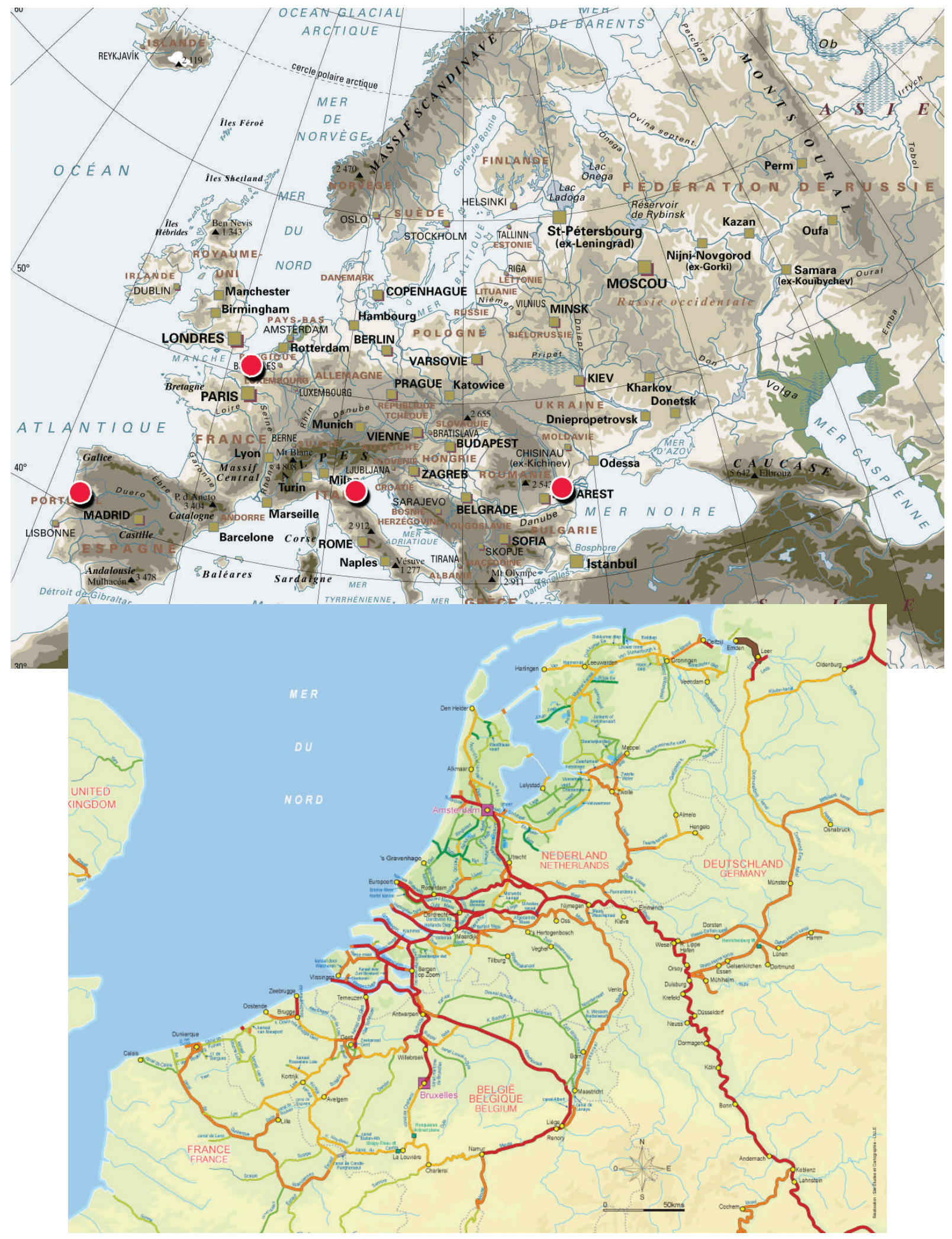




\section{Contexto}

\section{Lille e o programa europeu EPAT}

Desejosa de valorizar o seu rio e de reencontrar uma ligação entre a água e os seus habitantes, a Câmara Municipal de Lille comprometeu-se com o projeto europeu "A água como património: requalificação das paisagens urbanas fluviais". Trata-se de um trabalho de cooperação entre quatro cidades europeias que partilham o mesmo desejo: Braila na Roménia (sobre o Danúbio), Coimbra em Portugal (sobre o rio Mondego), Comacchio em Itália (no delta do Pó) e por fim Lille (sobre o Deûle). A finalidade é a troca de conhecimentos, de partilha de boas práticas a fim de melhorar as políticas de ordenamento e de reapropriação dos cursos de água urbanos dos territórios mencionados. Este trabalho materializa-se na produção desta obra e de uma exposição constituindo verdadeiros guias para outros territórios que se colocam as mesmas questões.

\section{O contexto regulamentar francês para abordar o projeto}

Em França, a lei sobre a água, de 3 de janeiro de 1992, consagrou a água como um bem. No seu primeiro artigo é afirmado que "a água faz parte do património comum da nação" e que "a sua proteção, a sua valorização e o desenvolvimento do recurso utilizável, respeitando os equilíbrios naturais, é de interesse geral". Esta "patrimonialização" de recursos de água encontra-se em numerosos países e regiões do mundo, particularmente no Ocidente.

Isto remete para diferentes abordagens do valor da água, considerando, por um lado, a água como recurso natural e por outro lado observando os usos ligados à água. A patrimonialização da água inscreve-se pois simultaneamente numa lógica de preservação, de valorização dos usos (passados, presentes e futuros) e dos lugares que lhe estão associados.

\section{A geografia de Lille}

"A água, fonte de vida, é aqui nascente de cidade. Contudo, Lille não nasceu de um grande rio, mas as suas ilhas, os seus ribeiros, os seus pântanos e os seus canais deram forma à sua história. [...] Por toda a parte, em Lille mas também nos concelhos à sua volta - e de modo mais alargado em toda a região - foi preciso procurar, domesticar, canalizar, aprovisionar e sanear. [...] aqui como em outros lugares, a água é preciosa e deve ser objeto de todas as atenções. A água é um trunfo essencial para o porvir da metrópole, bem como para o futuro da humanidade e de todo o planeta."

2001, Lille au fil de I'eau, Lille: La Voix du Nord, Pierre Mauroy 


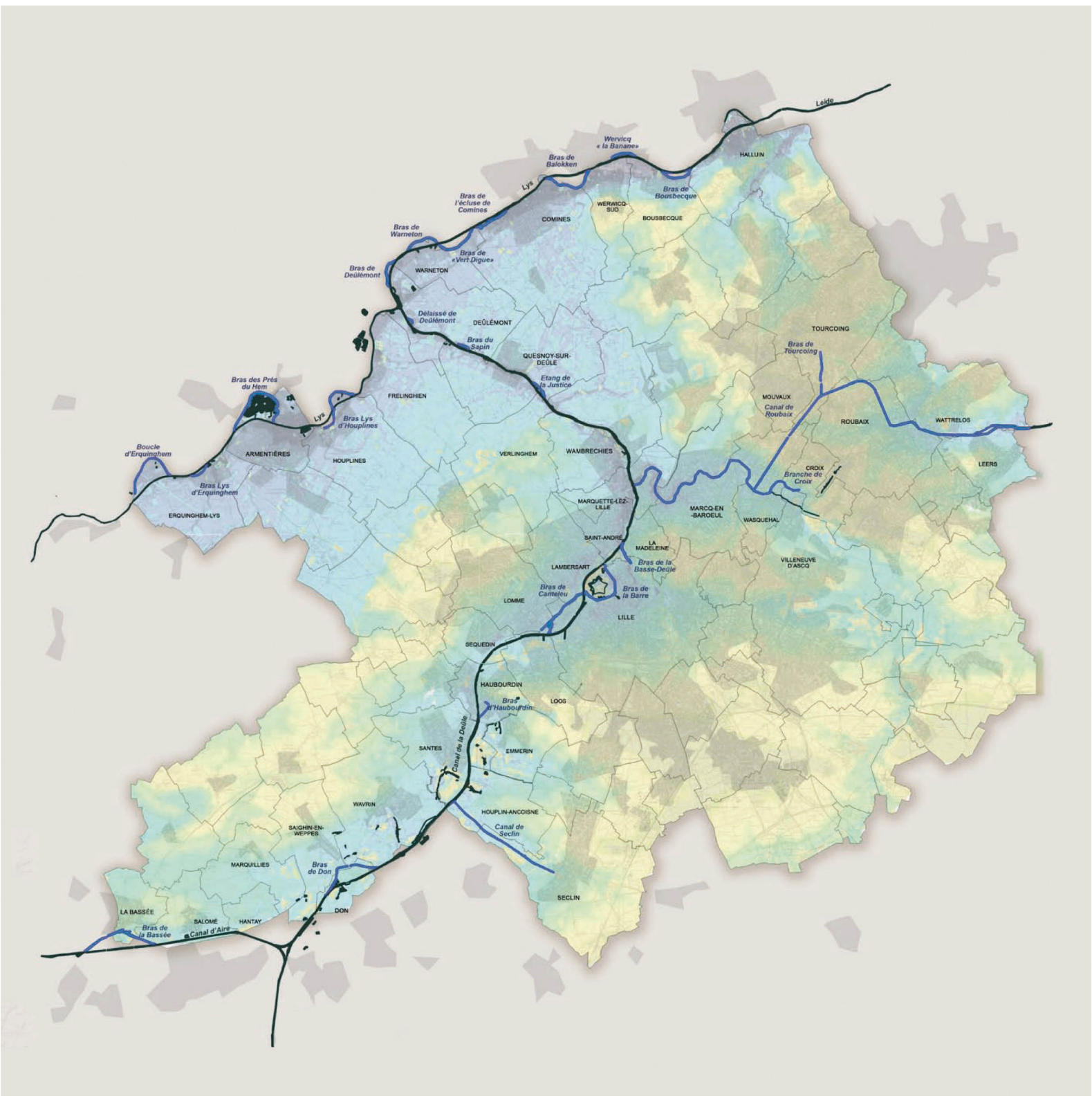

Os cursos de água (riachos, ribeiros, canais) representam atualmente no território metropolitano de Lille: $12 \mathrm{~km}$ de cursos de água dos quais $9 \mathrm{~km}$ navegáveis nos concelhos de Lille-Lomme-Hellemmes; $220 \mathrm{~km}$ de cursos de água, dos quais $84 \mathrm{~km}$ navegáveis, $60 \mathrm{~km}$ para o Deûle, no território de Lille Metrópole. O débito do Deûle é em média de $4 \mathrm{~m} 3 / \mathrm{s}$ em Wambrechies, a montante da confluência com o Marque. 


\section{Águas de superfície}

Historicamente, o território de Lille é um sítio de caráter fortemente húmido. Apresentava uma rede hidrográfica importante hoje desaparecida. O Deûle é o principal curso de água. Foi canalizado desde a Idade Média e o seu curso nunca cessou de ser modificado pelo ser humano. O Deûle tem a sua nascente em Carency no Pas de Calais, juntando-se-Ihe o Scarpe, a montante, e depois, no concelho de La Bassée, o seu débito passa para metade no canal de Aire em direção a Dunkerque. Por fim, junta-se ao Lys em Deulémont.

As funções dominantes do canal são: o transporte, o divertimento, mas tem também um papel hidráulico importante de drenagem no território que atravessa. O Deûle recebe as águas do canal de Marque Urbaine e do canal de Roubaix, servindo também de exutório para pequenos cursos de água e redes de saneamento dos concelhos vizinhos.

A supressão das bacias e vertentes hidrográficas e hidrogeológicas testemunha de uma comunicação entre o Deûle e o lençol freático do calcário. Em períodos de águas baixas, o lençol alimenta o Deûle e em períodos de águas altas é o rio que alimenta o lençol freático. Os poluentes vão pois do rio para o lençol freático e ao contrário. Depois de numerosos esforços para gerir as descargas no curso de água, o Deûle renasce enfim após ter sido um dos rios mais poluídos de França.

\section{Águas subterrâneas}

Globalmente, o subsolo da região de Lille é um verdadeiro mil-folhas de terras e de rochas diferentes através das quais a água circula mais ou menos rapidamente. Vários lençóis freáticos mais ou menos consequentes sobrepõem-se e encontram-se portanto a alguns metros debaixo dos nossos pés, com níveis que variam em função das estações e das bombagens.

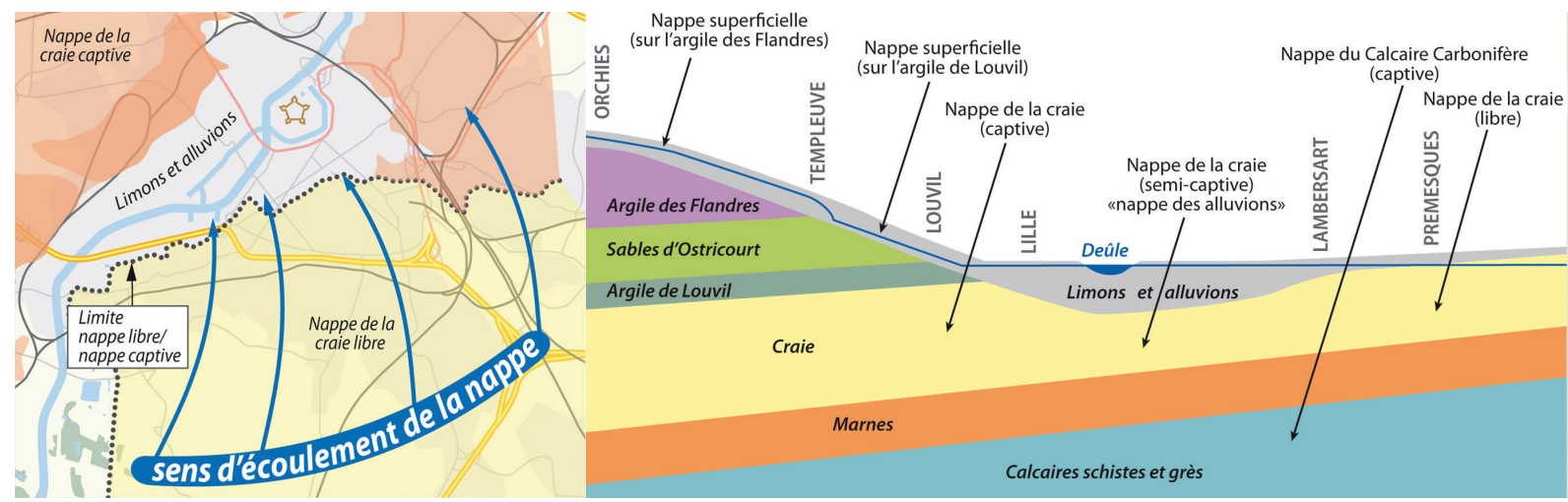




\section{A história de Lille}

O nome lembra o papel desempenhado pela água na cidade que construiu a sua história e a sua expansão graças a ela. "Trata-se de uma história tumultuosa entre a cidade e a água. Várias fases se foram sucedendo: a cidade alimentou-se da água, rejeitando-a em seguida a ponto de a renegar para, por fim, a reclamar de novo."

2001, Lille au fil de l'eau, Lille:

La Voix du Nord, Catherine Monnet

\section{L'Île-sur-la-Deûle}

Lille desenvolveu-se num sítio pantanoso e dotado de várias ilhas. O sítio foi por isso nomeado Isla, o que significa ilha em latim, e daí o seu nome atual, Lille. Os humanos instalaram-se nas margens do rio, e graças a ele conseguiram viver, levando a que, ao longo dos séculos, não cessassem de o domesticar, de o controlar, para dele tirar as melhores vantagens, antes de o rejeitarem progressivamente para fora da cidade no século XIX.

As descobertas arqueológicas revelam que o lugar foi povoado desde o Mesolítico por sucessivas populações, e que estas implantações estavam muito ligadas ao Deûle. No entanto, as implantações populacionais são muito ténues até cerca dos anos 750-800, período em que foi provavelmente criado o primeiro porto. No século IX o impacto das perturbações normandas provoca a fortificação de uma área habitada, ocupada por uma comunidade mercantil. A localidade é citada pela primeira vez em textos de 1066.

\section{Por que razão os humanos se instalaram aqui?}

Diversos braços de água enlaçavam as ilhas, com uma queda de água que, para os primeiros habitantes, representava uma fonte de energia. Uma primeira comunidade instala-se neste lugar que the oferece a possibilidade de atravessar o rio a vau, ao mesmo tempo que a queda de água obriga as primeiras embarcações a desfazerem-se da sua carga antes de passar o obstáculo, para recarregar a montante ou a jusante. Lille tem assim, pela primeira vez na sua história, uma posição de entroncamento.

Os numerosos cursos de água presentes na cidade são, ora ramificações naturais do Deûle e do Becquerel, ora testemunhos de antigos fossos protetores dos sucessivos recintos que nunca foram preenchidos, ou ainda canais escavados por razões económicas ou para ligar diferentes canais entre eles. 


\section{O rio Deûle no centro de todas as estratégias urbanas}

Até ao Renascimento, a água estava muito presente na cidade, no interior das muralhas e na base destas. Peleiros, curtidores de peles, fabricantes de papel, lavadeiros, talhantes, tintureiros e outros artesãos estabeleceram-se na proximidade da água, onde o gado e os animais de carga se desalteram, onde os portadores de água se vão reabastecer, onde os moinhos vão buscar a sua energia.

\section{A Cidadela}

Em 1667, Vauban decide implantar a Cidadela no lugar menos acessível das cercanias de Lille e no ponto mais baixo: escolhe pois um terreno pantanoso, impróprio para manobras militares de ataque. A Cidadela só podia ser atacada do lado da cidade, o quer obrigava o inimigo a empreender dois cercos de ataque: o da cidade e o da Cidadela. Os trabalhos, começados em 1667, terminaram em 1672

O plano de implantação da Cidadela foi pensado tendo a água como elemento defensivo a fim de interditar o acesso ao território (mediante inundação) mas também como elemento de ligação (através da navegação).

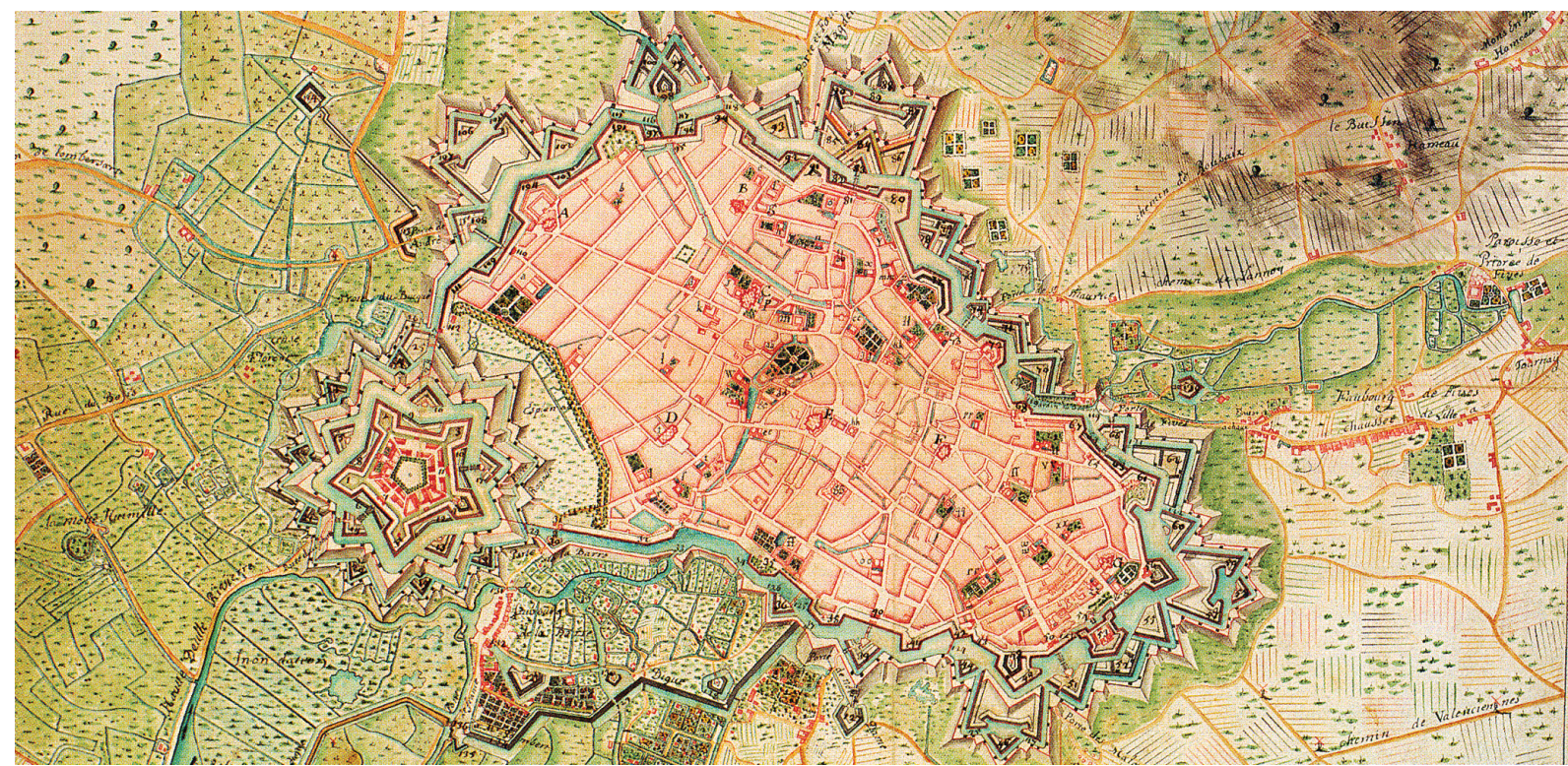




\section{O rio Deûle rejeitado para fora da cidade}

Perdendo a sua função económica no interior da cidade e cedendo ao espírito das Luzes que tendia a pôr fim às práticas de utilização da água, a cidade vai ser progressivamente "desidratada" durante dois séculos. Por volta de 1850, a construção do canal do Médio Deûle, inverte a problemática urbana da cidade de Lille. A água deixa de ser um fator de desenvolvimento no interior para passar a ser um sistema de navegação independente fora da cidade.

A ampliação de Lille, em 1858, modificou muito amplamente a rede hidráulica da cidade, cuja forma urbana deve ao mesmo tempo adaptar-se à chegada do caminho de ferro em 1848 . 0 transporte fluvial sofrerá doravante a concorrência do carril. Em contrapartida, para lá da via de água, é uma nova visão da água que se impõe na cidade: torna-se o elemento non gratus, e os canais são cobertos ou preenchidos.

O objetivo de maior salubridade vai motivar os grandes trabalhos do século XX. O plano de 1858 reflete o princípio de um enorme estaleiro e a remodelação em profundidade da cidade. A água já não é um elo de ligação entre os quarteirões. O Deûle forma uma barreira. Cada vez mais poluídos, os canais interiores vão ser progressivamente preenchidos até desaparecerem.

No início do século XX, os antigos canais são transformados em esgotos. Nos anos 30 começam os trabalhos de preenchimento do Baixo-Deûle e acabam nos anos 60. Em 1948, é criado o Porto fluvial, reforçado pela escavação do canal de grande dimensão nos anos 70 .

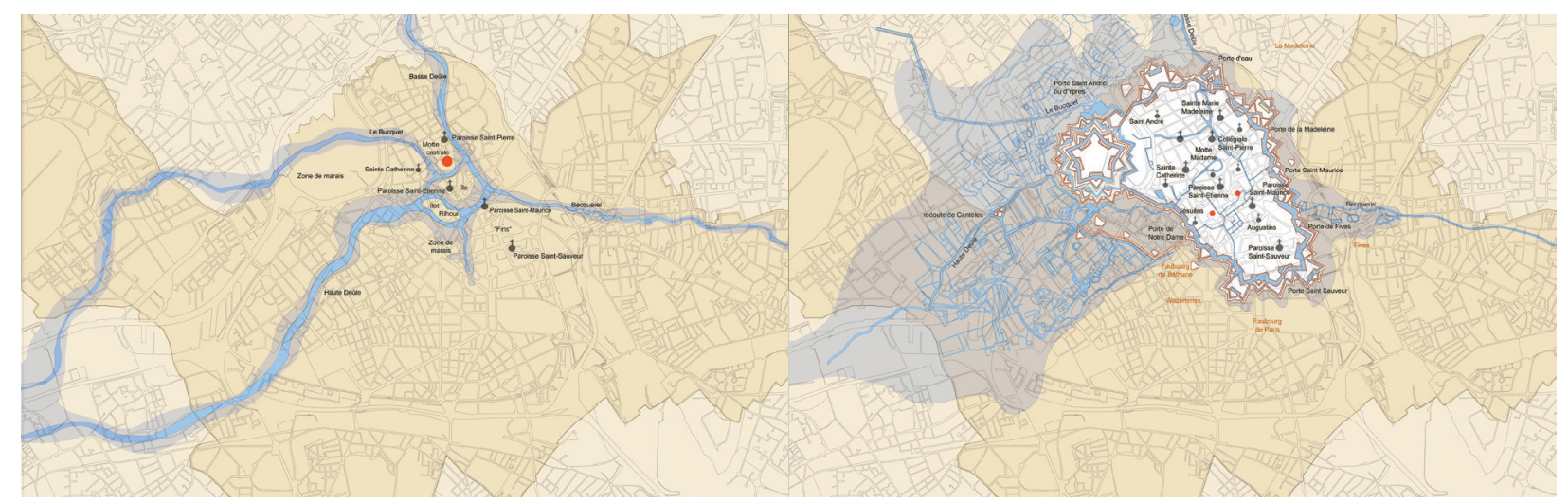

Ano 1000, os homens instalam-se nas ilhotas no meio do pântano. O curso de água passa pelo coração do que é hoje o centro da cidade.
A intervenção de Vauban, no final do século XVII, marca o apogeu do uso da água como sistema defensivo e comercial.

\section{Síntese}

Espaço identitário, o rio Deûle e os seus antigos canais constituem um elemento de memória do lugar, um bem transmitido, um património que hoje importa revelar e tornar acessível ao maior 
número de pessoas. Trata-se de inventar para ele um novo destino, novos usos, a fim de o pôr em acordo com as aspirações e necessidades da época.

Lille nasceu da água e, depois, virou progressivamente as costas ao seu rio. No presente, é tempo de fazer de novo falar a água e recriar laços com o Deûle. Projetos urbanos como o das Margens da Haute-Deûle com Euratechnologies começaram a empreender esse trabalho de costura do território. Outros se seguirão, tal como o porto e a estação de água de Lomme mas importa não limitar a intervenção ao urbanismo, ao ordenamento da via de água e pensar a atividade económica, a vida à beira da água. A invenção de um novo destino para esta rede capilar complexa e sensível e a promoção de novos usos, com vista a uma resposta em conformidade com as aspirações e as necessidades do nosso tempo, é uma tarefa de todos (eleitos, técnicos, empresas, associações, habitantes).

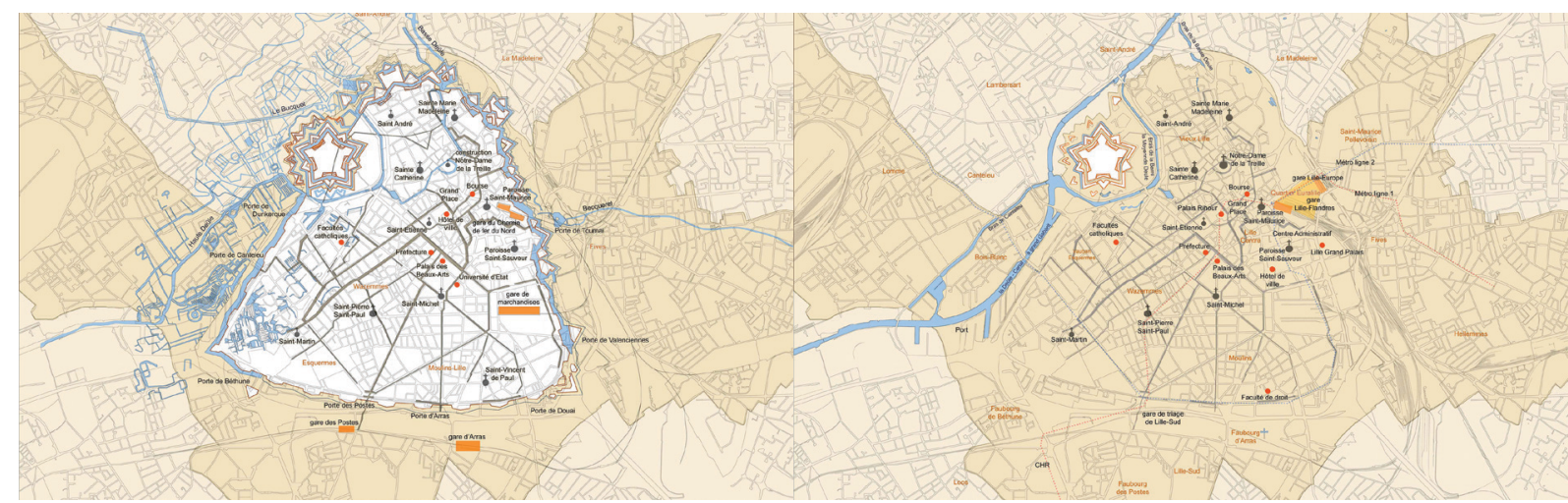

1858 - A cidade acaba de ser ampliada, anexando os arredores a sul. É o início do desaparecimento da água.
Anos 70 - Criação do canal de grande dimensão, última grande intervenção sobre o nosso território. Início da redescoberta da água.

\section{Leitura do território e estratégia urbana (para a água/pela água)}

\section{Diagnóstico do território}

Metodologia: Realização de visitas de terreno que revelaram características próprias de cada espaço (acessibilidade, morfologia, usos) e permitiram distinguir as situações urbanas e paisagísticas muito contrastadas.

O recorte distingue as situações, associando cada entidade a um espaço público ligado à via de água, determinando no seu funcionamento e no seu desenvolvimento. 


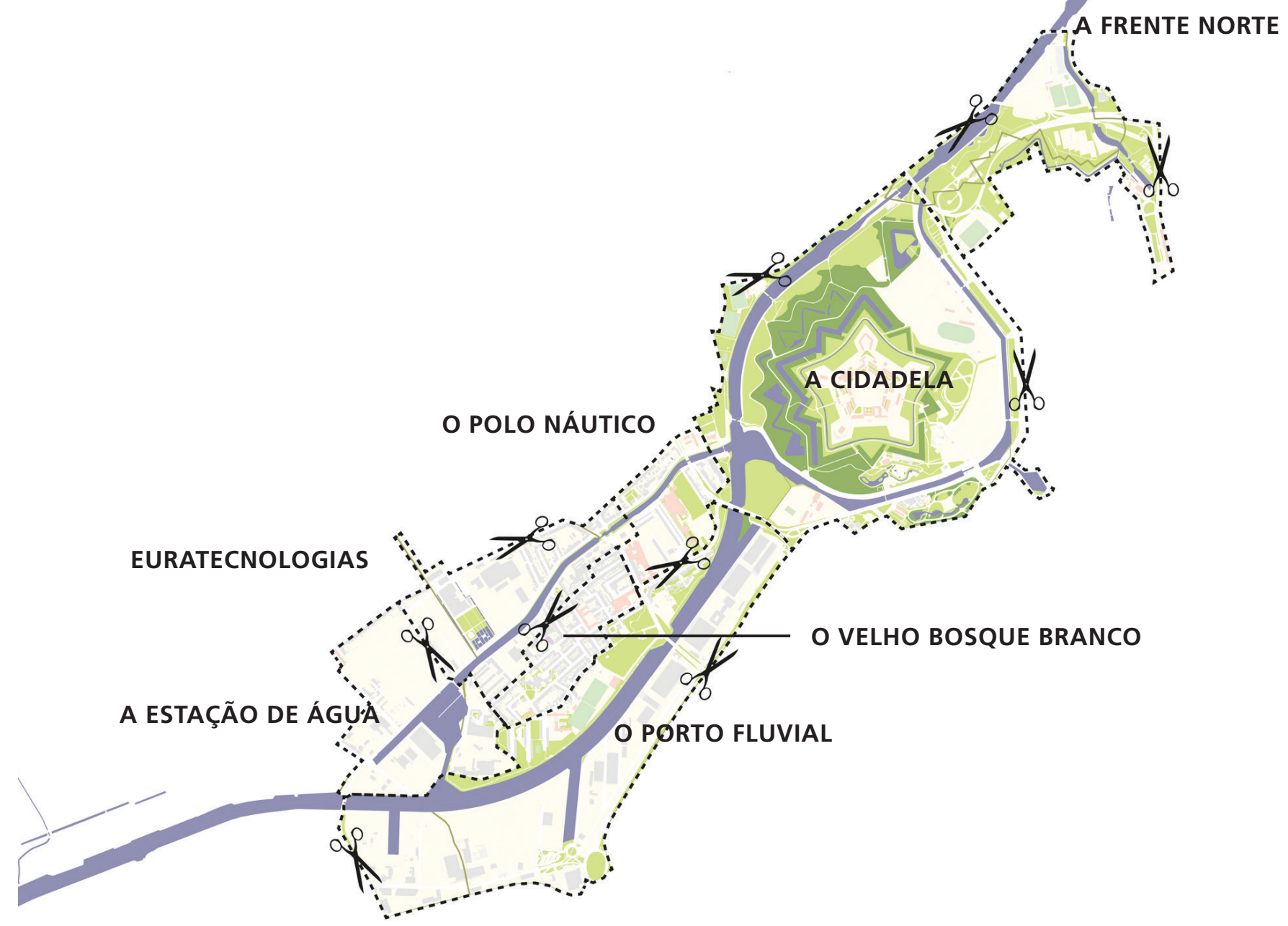




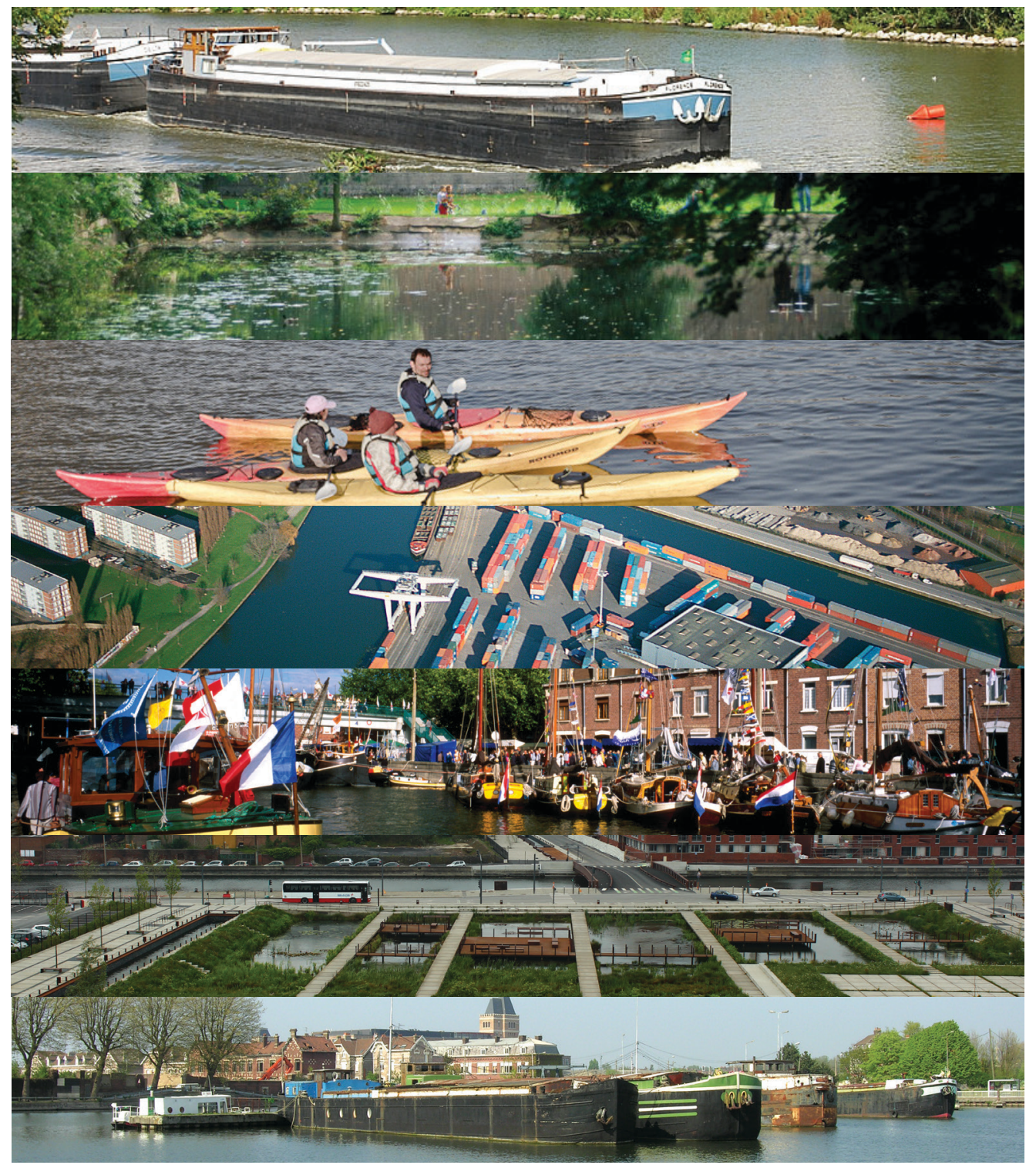

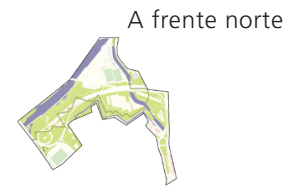

A Cidadela

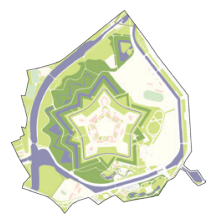

O polo náutico

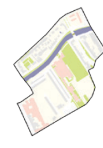

O porto fluvial

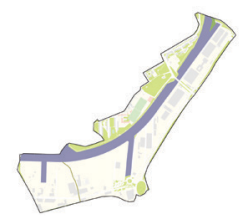

O velho bosque branco

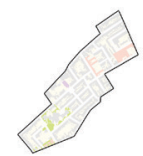

Euratecnologias

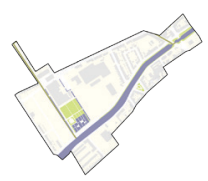

A estação da água

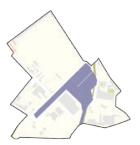


Vista aérea de Lille - Setor Oeste - 2003

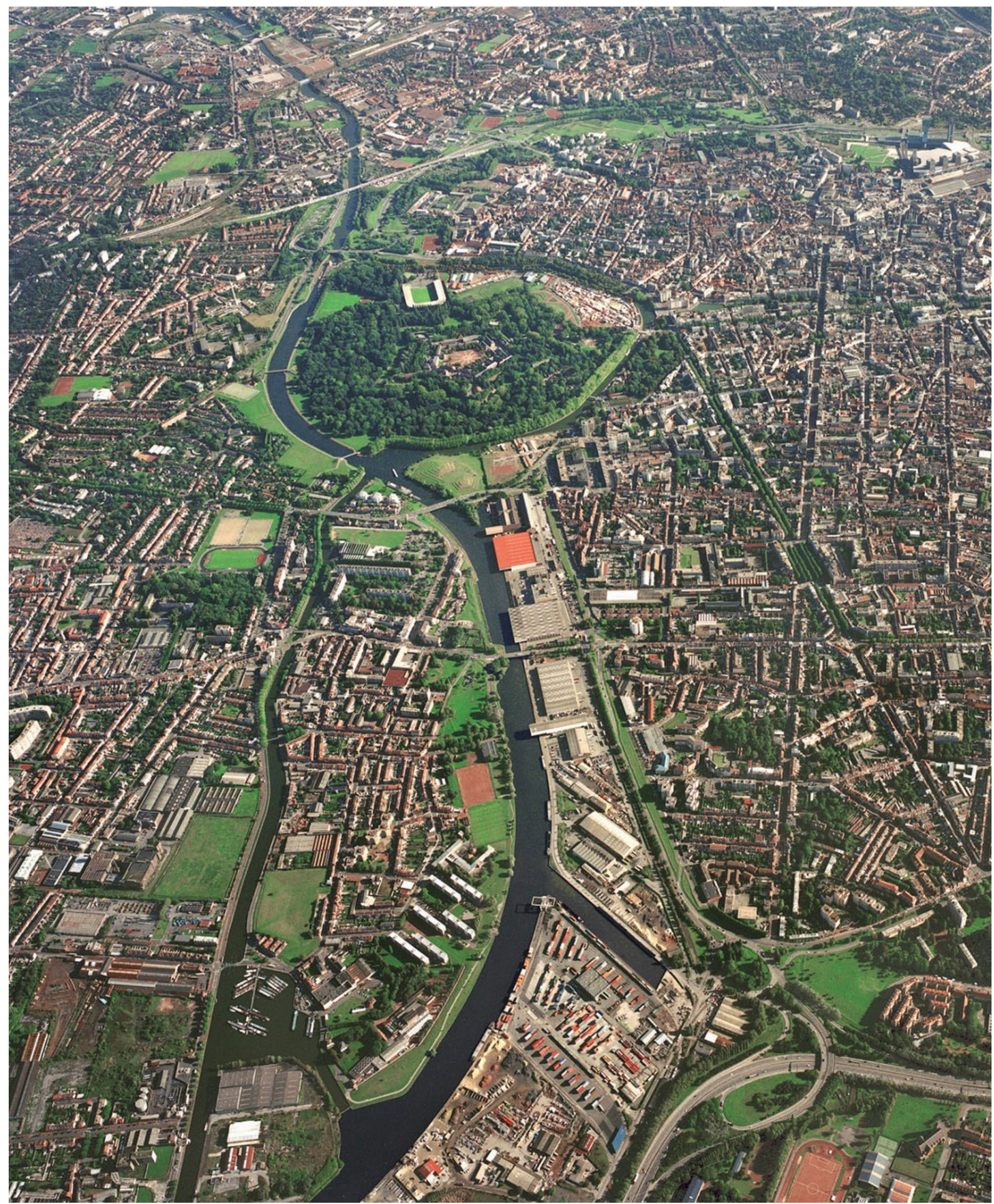




\section{A estratégia de Lille relativamente à valorização urbana da água}

Em Lille, as transformações urbanas vão intensificar-se com mais de 3000 novos habitantes à beira de água até 2016. A via de água torna-se de facto um elemento central da requalificação urbana e do retorno da cidade ao seu rio. Numerosos projetos urbanos desfilam assim no fio da água.

Estas mutações podem trazer atividade, atratividade, melhorando o quadro de vida dos habitantes e logo a imagem, a irradiação de Lille e da sua metrópole graças à água. Estas mudanças devem ser pensadas, enquadradas, daí a necessidade do Esquema diretor das águas de Lille (S.D.E.L. - Schéma directeur des eaux de Lille).

O SDEL tem um objetivo claro: proteger, economizar e valorizar a água, todas as águas, quer elas sejam potáveis, usadas, pluviais, de superfície ou ainda subterrâneas. Obra de referência para a água em Lille e na sua metrópole, este guia prático estabelece o ponto da situação em que se encontra o recurso, elabora a lista das potencialidades e propõe projetos. Faz igualmente o inventário dos atores incontornáveis, para saber quem faz o quê pela água no nosso território.

O SDEL é um documento mas constitui sobretudo a materialização de uma diligência municipal piloto que apreende pela primeira vez a água no conjunto do seu ciclo e no território de Lille - com uma visão metropolitana - a fim de conduzir uma ação coerente.

Por isso, este guia apresenta abordagens históricas, socioeconómicas e ambientais da água, sem esquecer a sua governação. Este documento convida a mudar a perceção que temos da água e a modificar as nossas práticas, os nossos comportamentos, porque a água é um assunto que a todos diz respeito.

Para responder a estes objetivos, a câmara de Lille rodeou-se de uma equipa constituída por especialistas em todos os domínios em causa (história, urbanismo, arquitetura, hidrologia, hidrogeologia, ecologia, sociologia, navegação e desenvolvimento da via de água), a fim de realizar um diagnóstico e de formular propostas de ação pluridisciplinares.

As diligências do SDEL e do projeto europeu EPAT "Água como património" fecundaram-se mutuamente, permitindo-nos ter uma reflexão que vai do local ao global. 


\section{História}

No passado, a relação mantida entre o Homem e a água foi sempre ambivalente. Inicia-se na simbiose, passando pela utilização e a seguir pela domesticação para acabar com o seu desaparecimento e destruição. Assim, os habitantes de Lille souberam desenvolver-se graças ao rio Deûle, por vezes às suas custas. Hoje, muitos procuram reencontrar essas raízes aquáticas, (nomeadamente através do patrimínio urbano).

\section{Sociologia}

Fonte de interrogação e por vezes de receio, a água é um tema que interpela. Habitantes e utentes procuram hoje uma nova relação com a água. Querem conhecê-la melhor, a fim de meIhor a desfrutar. Paralelamente, a água ocupa um lugar de destaque no ordenamento urbano, sendo um elemento de atração para as cidades.

\section{Ambiente}

A água perdura como fonte de vida e como um dos meios de aumentar a biodiversidade urbana. Este recurso aquático permanece frágil, precioso e felizmente submetido a uma atenção crescente.

\section{Economia}

A dinâmica de Lille pode ser amplificada pela atividade ligada à água ou à beira da água (empregos, alojamentos, lazer, etc.). Existe uma enorme quantidade de novas utilizações que podem vir a ser desenvolvidas, como acontece no estrangeiro.

\section{Governação}

O mundo da água é complexo e o jogo de atores envolvidos é ainda mais complexo. Este recurso sofre por vezes da multiplicidade - no entanto necessária, dada a plêiade de profissões - dos seus protagonistas. Daí a necessidade de desenclausurar as ações e de trabalhar de modo transversal.
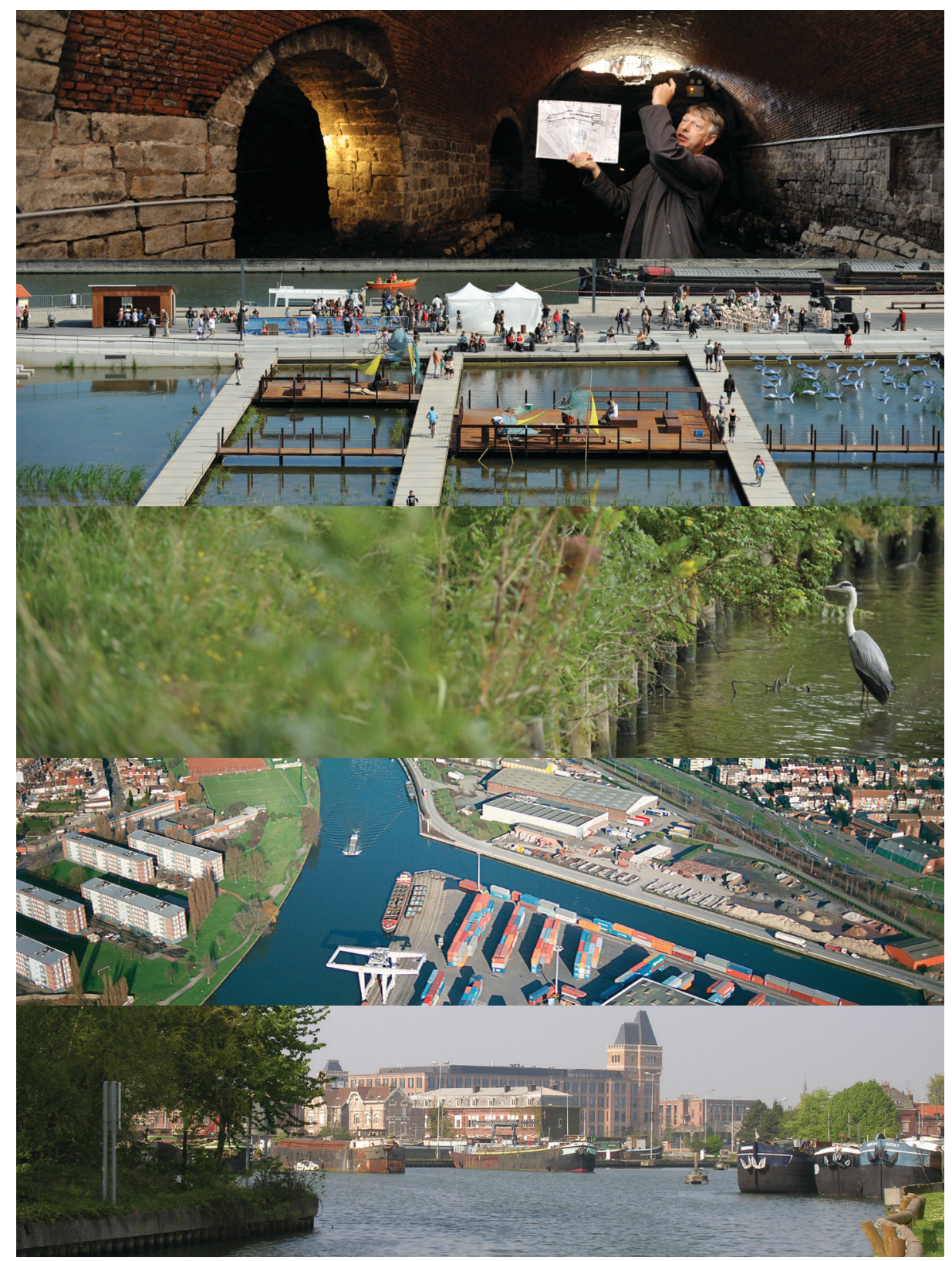

Quanto mais nos interessarmos pela água, maior será a consciência de que ela está por todo o lado. Omnipresente e por vezes cruelmente ausente, pode ser ao mesmo tempo visível e invisível, benfeitora ou perigosa, trunfo e fraqueza. É nesta perspetiva exaustiva que se inscreve o Esquema diretor das águas de Lille (SDEL), abordando a água em todos os seus aspetos. 
A água, o rio - tanto nas suas dimensões históricas como no seu devir - apresentam-se hoje como um meio evidente e eficaz para aproximar os habitantes da sua cidade e melhorar as suas condições de vida.

Lille possui com efeito um potencial inexplorado e poderia tirar mais vantagens do seu rio. É, pois, tempo de dar a palavra à água e de voltar o olhar da nossa cidade para o seu rio, movimento que é conhecido em todas as grandes metrópoles: Lille não deve deixar de entrar nesta corrente urbana.

Repensar a água na cidade significa reintegrar o conjunto destes projetos num processo coerente de valorização da água na cidade. Esquecido ou menosprezado durante muito tempo pelos seus habitantes, o Deûle dispõe agora de uma oportunidade única de se reinscrever no tecido urbano de uma maneira mais coerente.

Lille deve desde já reconciliar-se com as suas vias de água, valorizar este elemento natural no ordenamento dos seus espaços públicos e preservar este património. A noção de integração da água no ordenamento urbano precisa de uma visão global do território e de nele discernir as especificidades locais.

A relocalização do Porto Fluvial, a requalificação do Parque da Cidadela ou ainda o projeto de Coeur de la Deûle, na confluência com os braços da Basse Deûle, têm em comum a sua ligação ao canal. Numa escala mais vasta, esta porção de território lillois inscreve-se no projeto regional do Parque do Deûle, e de Trame Verte et Bleue.

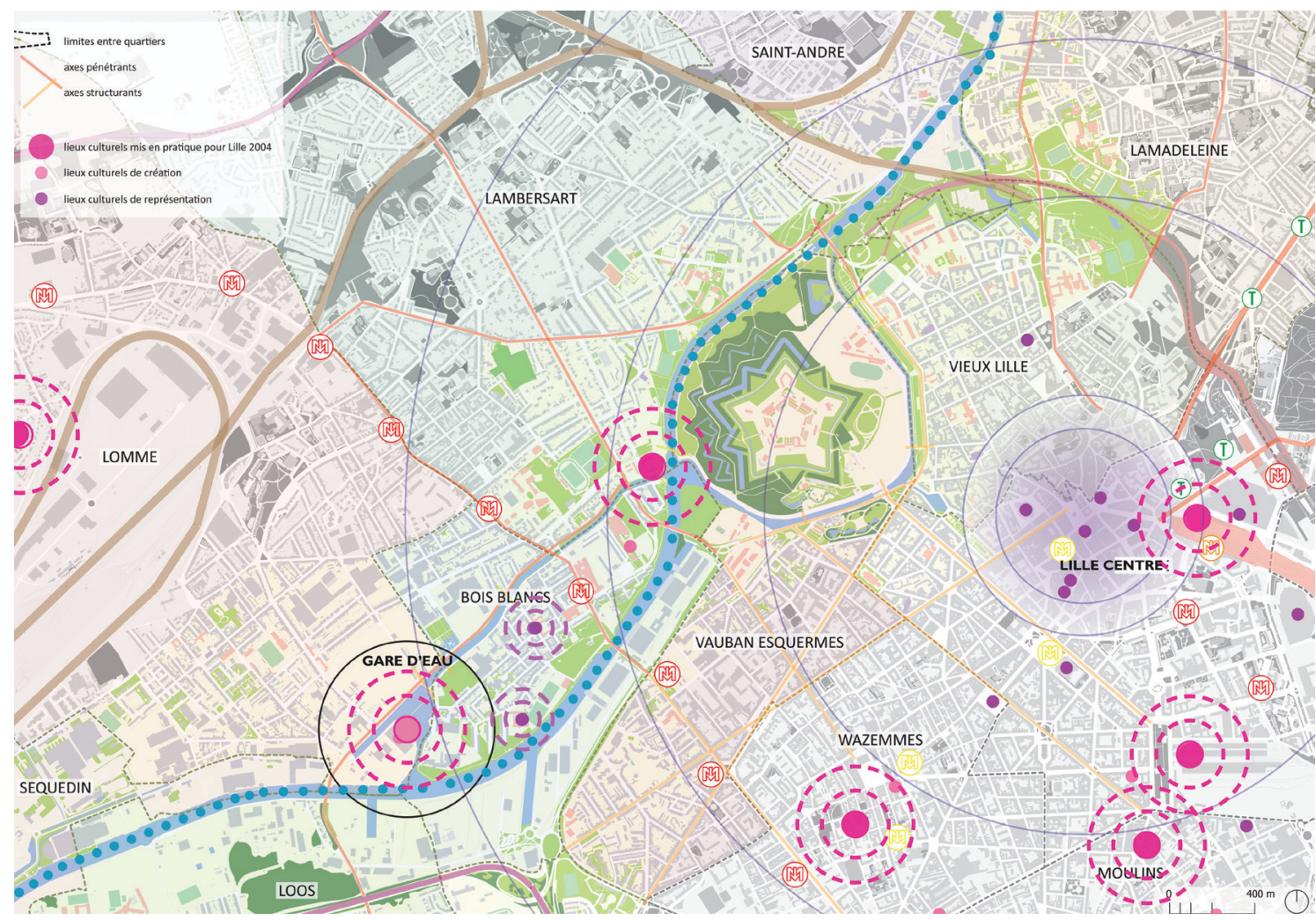

Os lugares culturais em Lille 


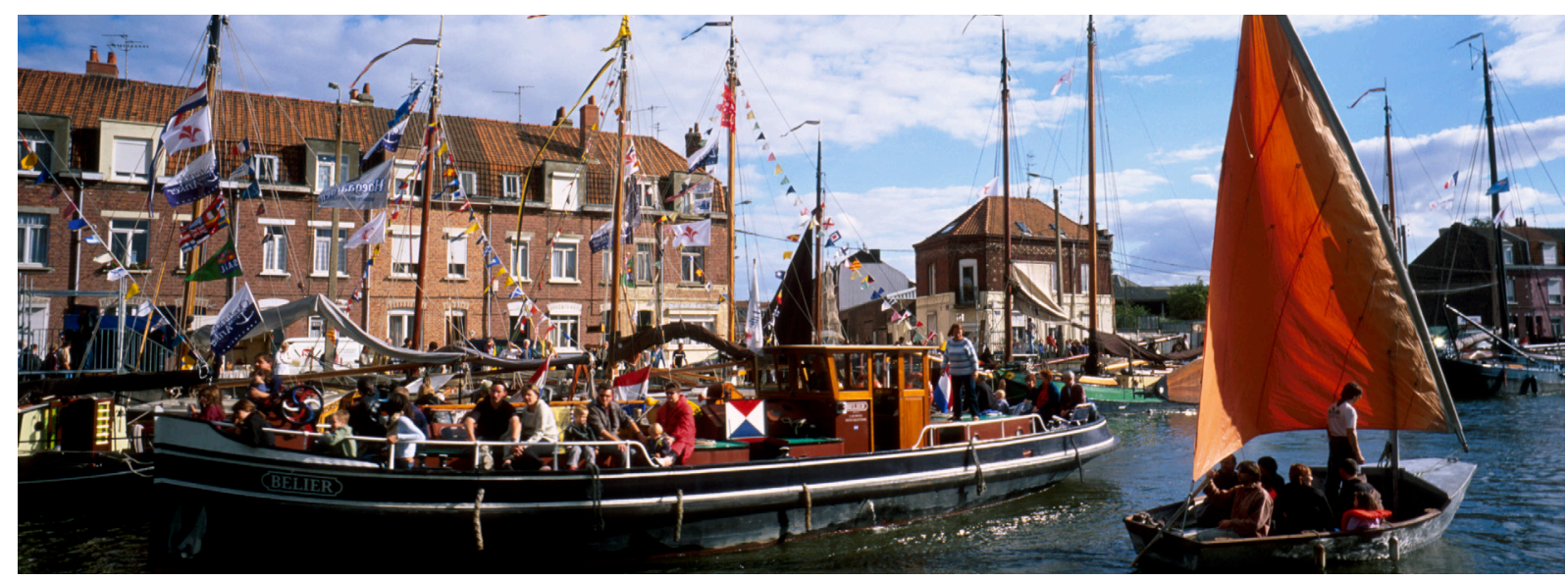

Canal de Canteleu - Bois Blancs - Jornadas do Património, 2004

Reconciliar a cidade com a água.

Hoje, o Deûle sofre de uma má imagem herdada do passado, o que não incita os habitantes de Lille a passear nas sua margens e a aventurar-se nas suas ribas. Ora, é precisamente porque as margens do rio são pouco frequentadas que a imagem do rio não muda.

O Deûle oculta um grande potencial para o desenvolvimento socioeconómico de Lille e para melhorar a sua imagem. Paralelamente, existe da parte dos habitantes uma forte procura de espaços de natureza e de animação à beira de água. Parece pois necessário agir para valorizar a via de água, o que favoreceria a reconciliação dos habitantes com o seu território.

A câmara de Lille empreendeu pois uma reconquista do Deûle com projetos urbanos de envergadura, mas estes poderiam ser mais fácil e rapidamente apropriados pelos seus habitantes se fossem acompanhados de animação, de acontecimentos culturais com vista à descoberta dos lugares.

\section{O papel da água na cultura e na animação de Lille}

\section{A cultura em geral em Lille}

Os desafios da política cultural de Lille são múltiplos mas têm o seu eixo central especificamente na criação, formação e sobretudo na acessibilidade do conjunto das populações, sem distinções sociais, à cultura. Esta vontade traduz-se na criação de um certo número de equipamentos e de acontecimentos.

A tónica recai igualmente na conservação e animação do património e no desenvolvimento da formação artística. Em última análise, a política cultural da cidade de Lille organiza-se em função de três grandes eixos: 
- Apoiar os artistas e a criação;

- Incrementar o acesso de todos os públicos à cultura e desenvolver a formação artística para os mais jovens;

- Fazer de Lille uma cidade de arte e inovação.

\section{Um rio Deûle pouco festivo em Lille}

As margens do Deûle formam uma continuidade verde e pedestre propícia às atividades desportivas e de relaxamento. No futuro, poderiam acolher acontecimentos culturais, concentrações populares.

Hoje, embora Lille tenha um índice de acontecimentos culturais de excelência (nomeadamente com Lille3000), poucos são os acontecimentos ligados à água, e não houve nenhum acontecimento de importância maior a celebrar o rio Deûle. Paralelamente, existe uma procura crescente de animações à beira de água por parte dos habitantes.

Apesar de existirem poucas animações em volta da água em Lille, o mesmo não acontece à escala metropolitana. Ainda existe um certo número de festividades, nomeadamente "a corrida à água", festa transfronteiriça, o festival "Deûle em festa", em algumas cidades desde Deûlémont até Lambersart fazemos notar que Lille não participa nessas festividades. Noutros lugares, as festas de "Saint-Vincent d'Automne" em Marcq em Barouel são também a ocasião de animação ao longo do rio Marque, bem como BlueDays sobre o canal de Roubaix. A acrescentar ainda as festas "guinguette" 4 e as praias estivais como acontece em Tourcoing ou Lambersart.

Existe em Lille um número significativo de associações e de iniciativas cidadãs relacionadas com a água e que propõem animações, acontecimentos culturais sobre a água, descobertas do rio, etc. Convém portanto não desperdiçar a riqueza própria deste terreno associativo como ponto de apoio. Paralelamente, existe uma crescente procura de animações à beira de água por parte das populações.

\section{O turismo fluvial, um manancial económico e de marketing subaproveitado}

Lille é uma cidade que dispõe de um potencial turístico real. Dois elementos culturais locais figuram no top 50 dos lugares de encontro mais visitados de França: a feira de liquidação dos comerciantes de Lille $\left(25^{\circ}\right)$; Parque Zoológico de Lille $\left(36^{\circ}\right)$. Por outro lado, Lille é uma das cidades mais visitadas de França, classificando-se em $184^{\circ}$ lugar a nível mundial de acordo com a agência Euromonitor. Este potencial continua no entanto ainda por explorar, sobretudo em termos de turismo fluvial. A proximidade

4 O termo guinguette designava, originalmente, pequenos estabelecimentos, do tipo do cabaret, instalados nas margens do Sena onde os populares se reuniam aos domingos para beber, petiscar, dançar e divertir-se à beira de água, praticando diversas atividades: regatas, canoagem, natação, etc.... 
de Lille relativamente à Bélgica e à Europa do Norte navegável oferece contudo saídas de mercado bem reais. Lille poderia tornar-se um destino privilegiado, uma etapa entre o norte da Europa e Paris.

Atualmente, 500 a 600 barcos turísticos transitam por ano na zona de Lille. Mas menos de 1 em 5 faz escala na cidade. Em causa está a ausência de paragens e de instalações que permitam a atracagem dos barcos.

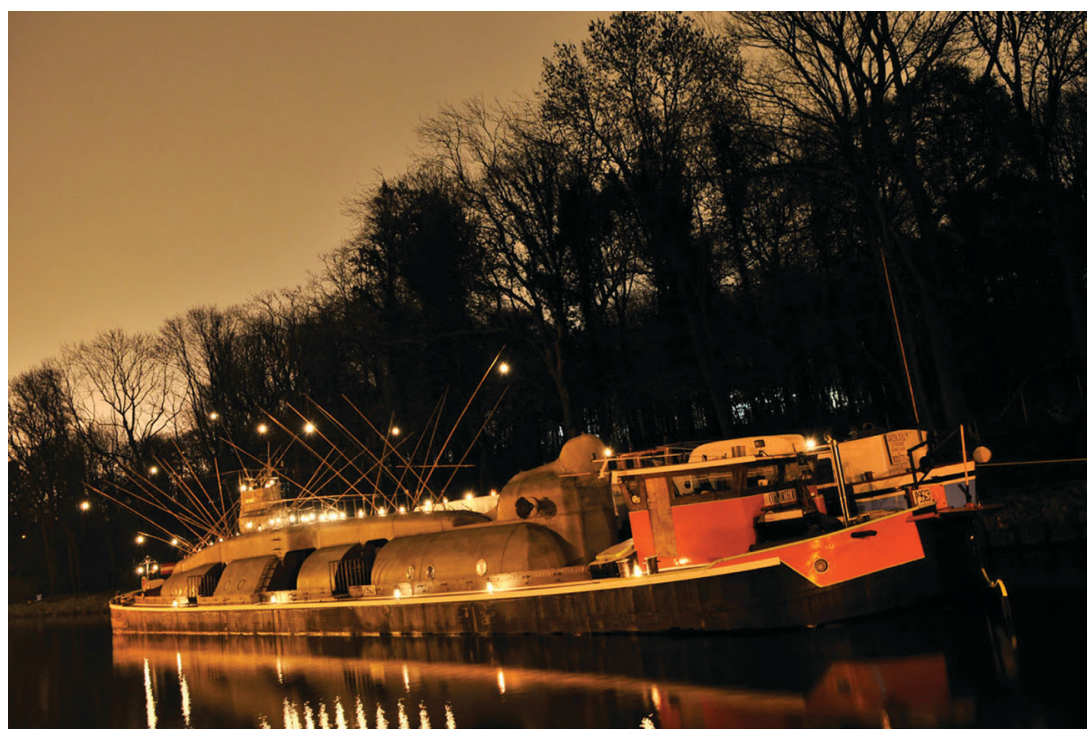

O Axolotl de Transporte Cultural Fluvial

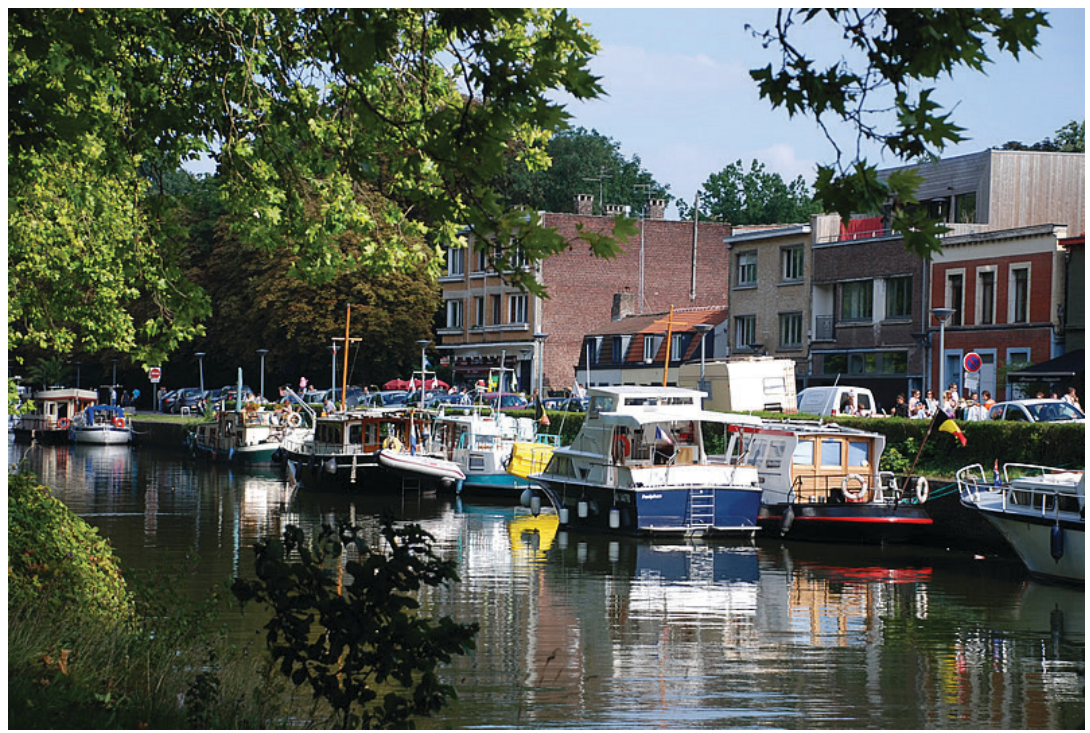

La Bras de la Barre - lugar de paragem para barcos de recreio em Lille 


\section{Do questionamento à problemática}

Lille nasceu da água, desenvolveu-se graças ao seu rio. Com o tempo foi-se estabelecendo uma relação entre o Homem, a água e a cidade. Antes de ser industrial, a água foi primeiro mercadora, depois militar. E agora? Que valores detém hoje e vai ter amanhã? Água como ambiente? Água como património? Água como cultura? Fica a interrogação.

\section{questionamento}

No início do seminário, havia um tema para Lille: A água como suporte de acontecimentos culturais. A nossa reflexão avançou, evoluiu. Transformámos assim o tema em problemática.

Como estabelecer a dimensão cultural do rio Deûle para fazer dele um espaço mais utilizado e mais vivo? Que lugar para a cultura nesta nova relação de Lille com a água?

Será que Lille quer realizar acontecimentos sobre a água e por consequência escolhe os lugares em função das suas necessidades?

Trata-se de uma ação por objetivos: Transpõe-se um acontecimento para a água.

Ou será que a água é um terreno, um meio identificado que permite levar a cabo acontecimentos que vão adaptar-se ao lugar?

Trata-se de uma ação por potenciais: Fazer com a água. Dois modos de agir diferentes para um mesmo resultado. Duas formas de fazer

\section{Do questionamento à problemática}

Convém privilegiar a abordagem por potenciais ao mesmo tempo que se definem objetivos claros. No entanto, estes devem adaptar-se aos potenciais do lugar.

Parece interessante privilegiar a abordagem cultural em vez da abordagem patrimonial.

Património = o que se passou = uma base/ uma herança

Cultura = dar vida a essa herança ao mesmo tempo que é enriquecida = Património de amanhã

\section{A problemática da cidade de Lille:}

Como estabelecer a dimensão cultural do rio Deûle para fazer dele um espaço mais utilizado, mais vivo? 


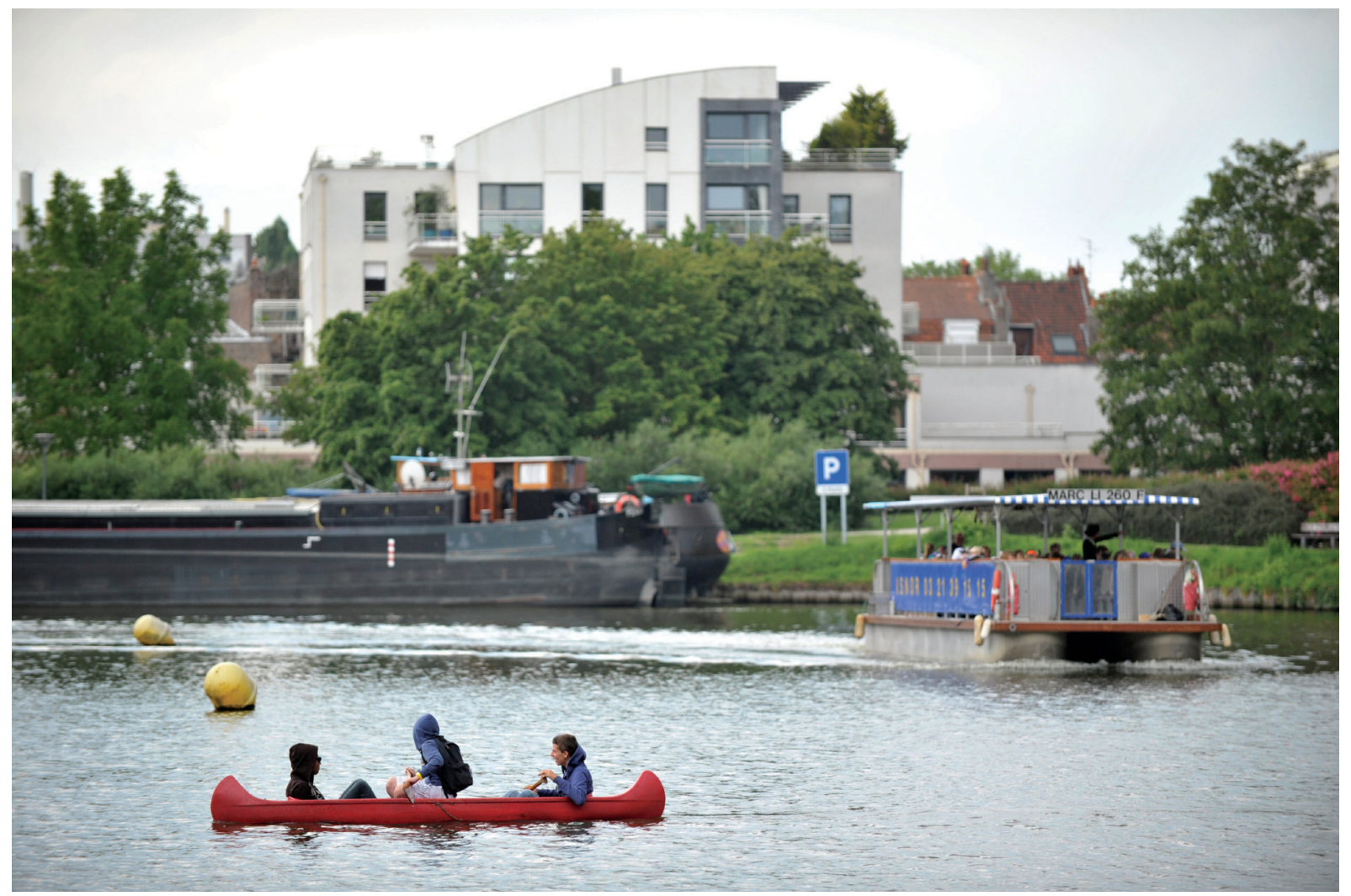

Utilização do rio Deûle 